Luis Adrián Rodríguez Cortés. Licenciado en Filosofía por la Benemérita Universidad Autónoma de Puebla (BUAP) con distinción Cum Laude. Maestro en Filosofía por la misma institución, también con mención Cum Laude. Director del Colegio Profesional de la Comunidad Mexicana de Estudiantes de Filosofía (сомefi). Coordinador del círculo de estudios "Philómytos" sobre historia y filosofía, en la Facultad de Filosofía y Letras.

Historial editorial Recepción: 17 de marzo de 2021 Revisión: 23 de marzo de 2021 Aceptación: 27 de mayo de 2021 Publicación: 28 de junio de 2021 


\title{
El mar sin orillas: una mitología filosófica del agua
}

\section{The sea without shores: A philosophical mythology of the water}

\section{O mar sem margens: uma mitologia filosófica da água}

\author{
Luis Adrián Rodríguez Cortés \\ Benemérita Universidad Autónoma de Puebla \\ luis.rodriguez_filo@hotmail.com
}

\section{Resumen}

El presente texto ahonda en los orígenes de la metafísica como ejercicio filosófico a partir de algunos relatos míticos de las civilizaciones egipcia y griega. Para ello, se rescata la figura elemental de "el agua", que, en sus diversas manifestaciones, expresa de forma latente cómo se relaciona el hombre con su origen más recóndito y los misterios que le circundan. Dicha inquietud pervive en la metafísica del siglo XVIII, a pesar de la carga racional que la recubre. En especial, la imagen del agua como vinculada a las fuerzas atractivas de lo desconocido se recupera en la obra de Immanuel Kant, quien caracteriza a la metafísica en la Crítica de la Razón Pura como un mar sin orillas, cuya exploración es la tentación de la razón. Mediante este ejercicio se presenta una indagación al respecto de los propios motivos del filosofar.

Palabras clave: Mito, Metafísica, Filosofía kantiana, Razón, Sinrazón. 


\section{Abstract}

This text aims to deepen into the origins of metaphysics as a philosophical exercise based on some mythical narrations from the Egyptian and Greek civilizations. For this, the elementary rescued figure from these stories is "the water", which, in its various manifestations, latently expresses the way in which man relates to his most recondite origin and the mysteries that surround him. This concern survives from the 18th century metaphysics, despite the rational burden that conceals it. In particular, the image of the water as linked to the attractive forces of the unknown, is revisited in the Immanuel Kant's work, which characterizes metaphysics in the Critique of Pure Reason as a sea without shores, whose exploration is the temptation of reason. This exercise is intended to investigate the philosophy's own motives.

\section{Keywords: Myth, Metaphysics, Kantian Philosophy, Reason, Unrea-} son

\section{RESUMO}

Este texto investiga as origens da metafísica como um exercício filosófico baseado em alguns relatos míticos das civilizações egípcia e grega. Para isso, resgata-se a figura elementar da "água”, que, nas suas várias manifestações, expressa latentemente como o homem se relaciona com a sua origem mais remota e com os mistérios que o rodeiam. Essa preocupação sobrevive na metafísica do século XVIII, apesar do fardo racional que a cobre. Em particular, a imagem da água ligada às forças atrativas do desconhecido é recuperada na obra de Immanuel Kant, que caracteriza a metafísica na Crítica da Razão Pura como um mar sem margens, cuja exploração é a tentação da razão. Por meio desse exercício, é apresentada uma investigação sobre os motivos do filosofar.

Palavras-chave: Mito, metafísica, filosofia kantiana, razão, irracionalidade. 


\title{
EL MAR SIN ORILLAS: UNA MITOLOGÍA FILOSÓFICA DEL AGUA
}

\author{
Los mitos despiertan en el hombre \\ pensamientos que le son desconocidos \\ Claude Lévi-Strauss, Mito y significado
}

El paso del mito al logos es una designación escolar que pretende trazar una línea fronteriza en la historia del pensamiento occidental, entre el imaginario mítico y las producciones mediante las cuales la razón se busca a sí misma, sin la mediación de los relatos vinculados con dioses y héroes. No obstante, desde los tiempos de Tales de Mileto, el pensamiento no ha avanzado un ápice en cuanto al conocimiento de las llamadas verdades últimas (o primeras) de la existencia. Esta situación es la que el filósofo polaco Leszek Kolakowski describe con las siguientes palabras: "Notable, sin duda, es la circunstancia de que no dispongamos de la energía espiritual que nos permita satisfacer nuestra curiosidad; pero todavía más digno de consideración es el hecho de que, aun sabiéndolo, poseamos la energía suficiente para seguir planteándonos los problemas" (12).

El presente escrito consiste en un esfuerzo por mostrar la vitalidad de los problemas irrecusables sobre el origen del hombre y su relación con el Todo, mediante algunos pasajes de la filosofía moderna, en los cuales resuena el eco de las inquietudes vertidas en la mitología, las cuales, como el oleaje del mar, no cesan de arremeter contra las arenas del pensamiento, a veces con tanta calma que nos parecen una parte armónica del paisaje, y otras en las que su fuerza titánica nos estremece, al grado de obligarnos a retroceder. Una disciplina privilegiada para mostrar la insuficiencia de la razón humana con respecto a sus intenciones totalizantes es, sin lugar a duda, la metafísica; por lo que no resulta extraño que se cuelen entre sus páginas algunas de las imágenes míticas que pueblan las páginas trágicas y cosmológicas de los pueblos antiguos.

Aclárese desde esta introducción que no se pretende homologar los campos ni las maneras de la filosofía y la mítica, que -en forma y materia - no pueden ni deben coincidir. Más bien, la tarea es mostrar las intuiciones míticas presentes en la metafísica, especialmente en la concepción kantiana de esta disciplina, o, en otras palabras, explicar los sueños de un metafísico a través de los sueños de la mítica. 


\section{EL AGUA, LA GENERACIÓN Y LA DESTRUCCIÓN}

Entre los relatos ancestrales que figuran en las mitologías de las grandes civilizaciones antiguas, los pasajes relacionados con el agua ocupan un lugar especial, que hermana a las diversas cosmovisiones bajo los signos comunes del diluvio y la fertilidad. Sumerios, hebreos, griegos y aztecas coinciden en narrar un azote catastrófico de lluvias tempestuosas e incesantes, debidas al designio de una deidad que, sintiéndose mal-correspondido o simplemente irritado a causa de los ingratos y escandalosos hombres, viene a renovar la generación de seres humanos. No obstante, cierta parsimonia envuelve la narración de tan terribles hechos, colocándola siempre en un pasado remoto, antes de nuestro tiempo. Por tal razón la lluvia nunca permanece odiosa al imaginario antiguo, ya que se reconoce en ella la mano divina que provee a la tierra de los frutos que alimentan a los pueblos. Esta marcada dualidad entre la fertilidad y la destrucción se comprende muy pronto en el pensamiento mítico como un par de caras de la misma moneda; así, por ejemplo, los antiguos egipcios ven en Osiris a un bondadoso rey del mundo de los muertos, "con poder sobre el agua, especialmente la de la inundación y sobre la vegetación” (Plutarco 15).

Los mitos del diluvio son, a la vez, mitos de la destrucción y la re-creación. En ellos, los dioses obran como agricultores que esperan recolectar frutos buenos sobre el terreno de viejas cosechas, dinámica que, si hay que expresarla en una sola palabra, puede llamarse "de la purificación”. En la imagen de la purificación queda saldada la relación entre los hombres y el agua, que, a fin de cuentas, permite la vida de la cual somos partícipes triunfales, aunque sea sobre el fango de nuestros antepasados. Por ello, todo diluvio se hunde en lo remoto de las civilizaciones; $y$, para continuar la dinámica de la vida agradable a los dioses y soportable a los hombres, hay que tener en cuenta la advertencia que representó este evento colosal, pero también la alianza renovada entre Dios y el hombre después de la destrucción, que nos provee la certeza de que "ningún ser viviente morirá por las aguas, ni habrá nunca más diluvio que destruya la tierra" (Génesis 9,11). Es decir, el hombre no puede vivir enemistado con las aguas, vitales para el desarrollo de la cultura y de las cuales obtiene su alimento, aunque en ocasiones éstas se tornen peligrosas. Por ejemplo, a pesar de las veces en las que el Nilo llegó a desbordarse, los egipcios se adaptaron al comportamiento de las aguas, hasta dominar los ciclos de la crecida del río. 


\section{El AgUA COMO ESPACIO Y Límite}

En todas aquellas ocasiones en las que la lluvia o los ríos que proveían el alimento fueron más allá de los cálculos y previsiones del pueblo, se hacía patente el poder de aguas menos cotidianas, cuya terrible manifestación resaltaba la ambigüedad del amable Osiris, mediador entre la vida y la muerte. Estas catástrofes prefiguran, a su vez, el carácter indómito de las aguas increadas, extrañas a toda función civilizatoria; en otras palabras, se trata de "aguas primordiales".

En Egipto, Nun fue una manifestación arcaica de las aguas de los mares. Esta deidad "representa el abismo del que todo surge, la indeterminación inicial de toda obra" (García 17), indeterminación que remite al imaginario occidental a la tradición hebráica de las aguas increadas, sobre las que el espíritu revoloteaba, y en las cuales fueron colocadas las terribles bestias marinas. En una tradición mítica posterior, ya con un pleno acercamiento a la cultura griega, la representación deídica egipcia de las aguas de los mares pasa a personificarse en Tifón, que, desprovisto de su carácter de origen primordial del todo, de acuerdo con Plutarco, significa “'estar cegado', 'estar loco', perfecto pasivo de typhóo" (Plutarco 63), e inclusive se le equipara al Dios del desierto: Seth. ¿Qué hace tan cualitativamente distintas a las aguas del mar de las aguas de los ríos, como para que la creatividad mítica reconozca en ellas personalidades divinas diametralmente distintas?

Lejos de constituir el principio de nutrición húmeda para la vida, el mar representa, en el imaginario egipcio, una extensión indómita y hostil a la naturaleza humana, como el mismo desierto. Plutarco escribe: "Osiris es el Nilo que se une con la tierra, Isis, y Tifón es el mar en el que el Nilo al desembocar desaparece y se dispersa, excepto cuanto la tierra recibe como su parte y al acogerlo en su seno se hace fértil gracias a él" (120). Así, el Nilo, el agua vivificadora, tiene presencia en todo lo vivo, mientras que las aguas del Mar tienen la capacidad de disolver aquel principio de fertilidad. Haciendo uso de este imaginario espacial, podemos ensayar la siguiente distinción: El agua del río, como principio de vida, llega hasta donde el agua de los mares la limita. Mientras los ríos se muestran como caminos transitables, el mar permanece como una amenaza constante de la disolución vital, que no puede encararse con las propias fuerzas, sin el riesgo de ser engullida en la inmensidad de lo intransitable.

A diferencia de la amenaza del diluvio, que porta la forma de un relato remoto, el mar posee una presencia constante en el paisaje, que no manifiesta otra cosa que una especie de peligroso sinsentido, pues, a fin de cuentas, es espacio intransitable, el cual, como toda alacena vedada, motiva la pregunta: ¿Qué hay allí? 


\section{El MAR, La Razón y La SINRAzón}

Los sueños del hombre moderno conservan a veces las mismas imágenes y metáforas que encontramos en los tratados eruditos de la Edad Media Carl Jung, Psicología y simbólica del arquetipo

Hasta ahora, explicamos a tientas algunas figuras de una tradición que temporal y espacialmente nos resultan lejanas, y, no obstante, puede apreciarse en ellas un atractivo universal, al cual difícilmente se le negará un grado de empatía. Hemos trazado los rasgos del imaginario mítico, que venera su relación con las aguas vivas y útiles, sin poder apartar la mirada de los mares indómitos y misteriosos ¿No es esta dialéctica la que anima al pensamiento metafísico, el cual no se contenta con la evidencia que la realidad ofrece a los sentidos? Aspiramos al menos, en esta sección, a definir si esta dialéctica se encuentra nutriendo la raíz del pensamiento kantiano.

Al mismo sabio de quien se dice pensaba que todas las cosas están compuestas por agua también se le atribuye la frase "Todo está lleno de Dioses" (Guthrie 37). Tales de Mileto, presumiblemente familiarizado con la cultura egipcia (Yoyotte 27) y específicamente con el culto a Osiris, mantiene el sentido elemental de la intuición deídica egipcia con respecto a las aguas que nutren y están presentes en lo todo vivo, sin embargo, este primer filósofo inauguró una tradición que omite el misterio de las aguas profundas, y propició la visión amistosa de las aguas claras que respaldan nuestra existencia, tradición que se extendió hasta el siglo xvir. ${ }^{1}$ En resumidas cuentas, aquí se afirma que - tal vez por un rasgo propicio para el examen psicoanalítico - la tradición filosófica predominante pudo tematizar sólo una relación armónica de correspondencia entre lo finito y su origen, entre el hombre y las aguas increadas. La cúspide de esta opinión es patente en la Teodicea de Leibniz, la cual —cristalizando la visión optimista del cosmos deísta- versa:

(...) muchos diluvios e inundaciones han dejado sedimentos de los que se encuentran rastros y restos, (...) Pero estos trastornos cesaron por último, y el globo ha tomado la forma que ahora vemos. (...) Pero ¿quién no ve que esos desórdenes han servido para traer las cosas al punto que se encuentran al presente, que a esto debemos nuestras riquezas y comodidades, y que por su medio se ha hecho este globo propio para ser cultivado por nuestros cuidados? Estos desórdenes han conducido al orden (Leibniz 275).

\footnotetext{
1 Pensar en alternativas dentro de la historia del pensamiento a la visión de un mundo de fuerzas ordenadas y sometidas por una razón primigenia resulta también fructífero. Las corrientes del hermetismo, por ejemplo, la de Zósimo de Panápolis en el siglo iII, nos muestran la imagen de una fuerza natural indómita y superior a la razón.
} 
Así como observamos que los mitos del diluvio encubren el carácter devastador de las aguas tras la narración de un pasado remoto, en el párrafo de Leibniz nuevamente atestiguamos la domesticación de las fuerzas acuáticas, que ahora sucumben por el orden racional de un Dios bueno y matemático, quien ha dictaminado desde el punto cero de la creación una cantidad justa de diluvios e inundaciones en nombre del mejor de los mundos posibles.

Es Immanuel Kant el primer pensador que devuelve su carácter profundo y misterioso a las aguas dentro de la tradición metafísica, sin dejarse arrastrar por alguna clase de locura marinera ni ser presa de un siempre latente naufragio, condiciones que bien podrían predicarse victimarias de los místicos y los escépticos, correspondientemente. Mas, para justificar nuestro juicio, citamos las palabras del propio Immanuel Kant al respecto de la metafísica, comenzando por la Crítica de la Razón Pura.

En la introducción de lo que llama "Doctrina trascendental del juicio", Kant pretende hacer un recuento de lo ganado hasta entonces por su proyecto crítico mediante una estética trascendental (sobre las condiciones de posibilidad de las sensaciones) y una analítica trascendental (sobre las condiciones de posibilidad del conocimiento a partir de los conceptos puros del entendimiento). Este recorrido arrojó la distinción entre el noúmeno y el fenómeno, es decir, entre aquello que es "En sî" - y por lo tanto independiente del entendimiento- y aquello que es objeto de una experiencia posible. De tan burdo resumen simplemente es menester rescatar que el entendimiento sólo puede hacer uso legítimo de sus conceptos en el campo de los fenómenos, abriéndose ante nosotros la brecha intransitable entre lo que podemos conocer y lo que deseamos conocer. Esta impotencia de la razón es expresada por Kant de la siguiente manera:

(...) el territorio de la verdad — un nombre atractivo — está rodeado por un océano ancho y borrascoso, verdadera patria de la ilusión, donde algunas nieblas y algunos hielos que se deshacen prontamente producen la apariencia de nuevas tierras y engañan una y otra vez con vanas esperanzas al navegante ansioso de descubrimientos, llevándolo a aventuras que nunca es capaz de abandonar, pero que tampoco puede concluir jamás. Antes de aventurarnos a ese mar para explorarlo en detalle y asegurarnos de que podemos esperar algo, será conveniente echar antes un vistazo al mapa del territorio que queremos abandonar e indagar primero si no podríamos acaso contentarnos con lo que contiene, o bien si no tendremos que hacerlo por no encontrar tierra en la que establecernos (Crítica 259).

En este fragmento de su primera Crítica, Immanuel Kant dota a la figura del mar de la extrañeza de antaño, que la caracterizaba en los episodios de la mitología que hemos someramente revisado en las páginas precedentes, y cabe suponer que este pasaje de la crítica 
- a pesar de estar colocado a la mitad de la obra- devela los móviles de la misma, que no son otros sino las emociones mixtas de terror y atracción que genera lo desconocido, eso que, en términos kantianos, podemos llamar "lo sublime", definido por atraer a la imaginación más allá del agrado. Tal es la fuerza de la metafísica.

Pocos años más tarde, ya cerca del final de su producción filosófica, Kant dirige una vez más algunas referencias marítimas para hablar sobre las aspiraciones de la razón: La metafísica — dice él— “es un mar sin orillas, en el cual el progreso no deja huella alguna, y cuyo horizonte no contiene ninguna meta visible con respecto a la cual se pueda percibir cuánto se ha acercado uno a ella" (Kant, Los progresos 6). Más adelante, como hechizado por el canto de alguna sirena, el filósofo suspira: "Sin embargo, lo intentaremos" (Los progresos 7). Esta última imagen - la de un hombre próximo a infiltrarse en terreno hostil-, es aquella que sirve de mejor manera para vincular a Immanuel Kant con grandes nombres de la mitología, desde Caronte a Odiseo, quienes no se lanzan al mar con la fuerza de sus propios brazos, sino armando una embarcación, lo más digna posible para la travesía, aunque se comprenda de antemano lo desgastante de una prolongada y difícil lucha, cuando no de una derrota ineludible.

\section{Viajes inconclusos: Kant y Caronte}

El inconsciente marcado por el agua soñará, más allá de la tumba, más allá de la hoguera, con una partida sobre las aguas Gaston Bachelard, El agua y los sueños

En la mitología griega, Caronte es el barquero que transporta las almas en su tránsito hacia el mundo de los muertos a través del río Aqueronte. Este río, que Virgilio describe como un abismo cenagoso e hirviente (Martin 35), evoca a nuestra imaginación la figura de aguas intransitables y prohibidas; tan es así, que resulta preferible para las sombras de quienes perecen llegar al mundo de los muertos antes que sumergirse en la disolución eterna en tales aguas. En ocasiones representado como un ente maligno y malencarado, las mayoría de las veces Caronte es concebido como un lúgubre anciano condenado, al estilo de Sísifo, quien — sin perversión — dedica su vida a la tarea incesante de mediar en el tránsito entre la vida y la muerte, con la sola condición de recibir una moneda inútil de parte del tripulante, tal vez, a manera de prueba de la condición del difunto como hombre libre. 


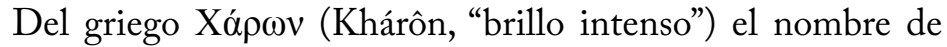
Caronte nos recuerda que otra manera de concebir la muerte es un viaje hacia la luz. Imagen que hace amable el destino del viajero, quien anda de paso sobre las aguas profundas, a la espera de llegar a un descanso eterno; pero este consuelo no es válido para el barquero, este es un eterno viajero, que, como el guardián de un faro, guía sobre olas tempestuosas a quien tiene un destino fijo más allá del mar. ¿No es tal la condición del filósofo? Quien se dedica a la filosofía proyecta sendas teóricas sobre caminos no definidos, de difícil o hasta imposible tránsito, sin que el carácter esquivo de la verdad detenga su labor. Al menos así puede describirse la trayectoria del profesor Immanuel Kant, quien caracterizó a la Ilustración —el advenimiento del brillo intenso- como una tarea constante para la humanidad, más que como la profecía de un destino inminente, mientras evitaba, sin lograrlo del todo, dirigir la mirada al territorio vedado de las aguas primigenias de la metafísica. Tal es la crisis que antecede a la crítica, cuya aproximación se ha intentado mediante este breve escrito, híbrido entre mitos y logos.

\section{REFERENCIAS}

Biblia de Jerusalén. Bilbao: Editorial Desclee de Brower, 1975.

Bachelard, G. El agua y los sueños. México: fce, 2003.

García, J. Dioses y símbolos egipcios. España: Ediciones Fausí, 1987.

Guthrie, W. Los flósofos griegos. México: fce, 1985.

Jung, C. Psicología y simbólica del arquetipo. España: Paidós., 1982.

Kant, I. Los progresos de la metafísica en Alemania desde Leibniz a Wolf. México: FCE, 2008.

- Crítica de la Razón Pura. México: Taurus, 2006.

Kola kowski, L. La presencia del mito. Argentina: Amorrortu, 2006.

Leibniz, G. Teodicea. Ensayos sobre la bondad de Dios, la libertad del hombre y el origen del mal. España: Biblioteca Nueva, 2014.

LÉvi-Strauss, C. Mito y significado. Madrid: Alianza. 1995.

Martin, R. (Dir.) Diccionario de mitología griega y romana. España: Espasa, 2005.

Plutarco. "Isis y Osiris". En: Obras morales y de costumbres. España: Gredos, 1995.

Yoyotт E, J. “El pensamiento prefilosófico en Egipto”. En: Parain, B (Coord.)

El pensamiento prefilosófico y oriental. México: Siglo xxi, 2009.

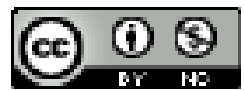

